\title{
A INSERÇÃO DA DISCIPLINA ECODESIGN NA MATRIZ CURRICULAR DOS CURSOS DE GRADUAÇÃO EM DESIGN: UMA NECESSIDADE?
}

The insertion of the Ecodesign discipline in curriculum disciplines of graduate in design: A necessity?

FRANCO, Annibal Gouvêa I Mestrando em Design

Universidade do Estado de Minas Gerais - UEMG

francoartedesign@gmail.com

PÊGO, Kátia Andréa Carvalhaes I Doutoranda e Sistemi de Produzione \& Design Industriale

Universidade do Estado de Minas Gerais I UEMG

katiapego@gmail.com

\begin{abstract}
Resumo
O presente artigo trata de uma pesquisa realizada com 15 escolas brasileiras que possuem curso de graduação em design. Tendo em vista a importância do ecodesign para a minimização de impactos ambientais negativos advindos do atual modelo de produção e consumo, acredita-se que a inclusão da disciplina Ecodesign é fundamental para que os designers possam atuar de maneira

\section{Abstract}

The present article analyzes a survey of 15 Brazilian schools that have graduation course in design. Given the importance of ecodesign to minimize negative environmental impacts from the current model of production and consumption, it is believed that the inclusion of the discipline Ecodesign is essential for designers to act in a systemic approach in the market.
\end{abstract} sistêmica no mercado.

Palavras-Chave: design; ecodesign; matriz curricular.

Key-words: design; ecodesign; curriculum. 


\section{INTRODUC̣ÃO}

Diante da recente crise ambiental, podemos observar várias ações em diversos setores que procuram empregar o conceito de desenvolvimento sustentável, que é aquele que "[...] atende às necessidades do presente sem comprometer a possibilidade de as gerações futuras atenderem às suas próprias necessidades" (COMISSÃO MUNDIAL SOBRE O MEIO AMBIENTE E DESENVOLVIMENTO, 1988, p. 46).

No âmbito do design, esta tendência se faz presente por meio da aplicação dos preceitos do ecodesign, cujo principal objetivo é desenvolver produtos, ambientes e serviços com redução dos impactos ambientais advindos do atual modelo de produção e consumo. A seleção de materiais menos impactantes, recicláveis, com qualidade maior e, eficiência no uso da energia, são algumas das ações preconizadas pelo ecodesign.

Sendo assim, o design também pode colaborar com a busca pela sustentabilidade ao projetar, além de dos custos, estética, ergonomia e tantos outros aspectos intrínsecos à sua atividade, a redução dos impactos ambientais do seu produto e/ou serviço.

Importante lembrar que "impacto ambiental" é qualquer interferência que ocorre no meio ambiente provocada pelas atividades do ser humano, seja ela positiva ou negativa. Em relação à produção de produtos industriais, os impactos ambientais são advindos do ciclo de vida dos produtos, envolvendo: pré-produção, produção, distribuição, uso e descarte dos mesmos. O campo de análise do profissional designer não deve se restringir ao produto, mas a todo o seu ciclo de vida, podendo então, efetivamente, proporcionar a minimização dos impactos ambientais negativos.

Como lembra Pêgo (2010),

Diante das evidências dos impactos ambientais causados pelos atuais modelos de produção e consumo, a mudança de atitude torna-se cada vez mais imprescindível. Nesse contexto, nós, designers, somos uma das peças chave para redução dos impactos ambientais. Como desenvolvedores de produtos industriais temos a responsabilidade, o desafio e até mesmo o dever de contribuir para a sociedade que busca a sustentabilidade (PÊGO, 2010, p. 7).

Por meio do melhor aproveitamento da tecnologia para a produção de 
itens que reduzam os impactos ambientais negativos, o ecodesign ${ }^{1}$ tem como principal objetivo o projeto de produtos, ambientes e serviços que sejam mais sustentáveis.

Sabe-se que o conceito de sustentabilidade ${ }^{2}$ é aplicado ao design quando este consegue suprir as necessidades das pessoas e/ou empresas, visando reduzir o comprometimento ao meio ambiente. Assim, o ecodesign torna-se uma importante ferramenta para que o designer aplique o conceito sustentabilidade em sua atividade projetual, minimizando os impactos ambientais decorrentes de sua atividade.

\section{REVISÃO BIBLIOGRÁFICA}

\section{Artes Industriais, Desenho Industrial e o Design no Brasil}

De acordo com Ribeiro (1985), em 1922, novas propostas de um grupo de jovens idealistas e patrióticos mostravam aos cidadãos paulistas que as artes também são dinâmicas e evolutivas. As nossas artes, especialmente a pintura e a escultura, experimentam novas soluções estéticas, adotam as propostas de novas correntes artísticas vindas do exterior e evoluíram. Esta revolução foi marcada pela "Semana de Arte Moderna", que ocorreu nos dias 13, 15 e 17 de fevereiro de 1922.

Logo após, a arquitetura se manifestou por meio da experimentação do Art Nouveau e do Art Decó. Em 1920/1940, residências e ambientes eram decorados em profusão com arabescos de ferro batido, azulejos coloridamente floridos, estatuetas com bailarinas nuas, grades com pássaros envolvidos em dinâmicas volutas, vitrais policromados e luminárias exóticas. Vez por outra, eram encontradas as convidativas "chaiselong" de Le Corbusier, a cadeira "Vassily" de Marcel Breuer, ou ainda uma poltrona do mestre Van der Rohe, mostrando elementos inovadores; para a época, o aço em tubos e chapas e, o couro natural ou trabalhado, são exemplos representativos da beleza elegante e funcional das formas pioneiras da Bauhaus. O Brasil, a partir da década de 60, trouxe consigo a criação de novos cursos de nível superior ligados à produção industrial; os cursos de desenho industrial, artes industriais e mesmo cursos de artes plásticas e desenho, estabelecem uma nova perspectiva para o ensino das artes, tanto no campo técnico quanto no campo teórico da história, da crítica e da estética.

Ainda segundo Ribeiro (1985), em 1963, no Rio de Janeiro, houve a instalação da Escola Superior de Desenho Industrial, para possibilitar a formação de novos designers, estes em permanente contato com as escolas européias e 1 Disponível em: <http://www.guiadacarreira.com.br/artigos/atualidades/engenhariaambiental-ecodesign/>. Acesso em: 01 jun. 2012.

2 Disponível em: <http://construcaoedesign.com/category/ecodesignsustentabilidade/>. Acesso em: 01 jun. 2012. 
norte-americanas.

\section{O Design e o Meio Ambiente}

De acordo com Cardoso (2008), por volta de 1973, foi a primeira vez em que o meio empresarial reconheceu que as matérias primas naturais eram finitas e que o seu custo estava fadado a se elevar cada vez mais. Durante a crise do petróleo, ocorrida nesta data, os países exportadores desse recurso impuseram um boicote aos importadores. Assim, abriu-se uma oportunidade para a difusão da mensagem do movimento ambientalista, que se difundiu por toda a sociedade.

Ainda na década de 70, de acordo com o autor, a indústria automobilística foi fortemente atingida pelo aumento dos preços de combustíveis, que marcou o fim dos carros americanos tradicionais e, deu início a uma nova era de carros mais compactos e econômicos. Essa situação promoveu no Brasil o Programa Pró-Álcool, com o intuito de tentar solucionar o grande problema da dependência das fontes de energia não renováveis. Atualmente, tais pesquisas pioneiras começam a obter resultados, através do recente interesse mundial pelo etanol como alternativa aos combustíveis fósseis.

Na década de 80, as preocupações com o meio ambiente vieram novamente à tona, e com ela, principalmente na Europa e na América do Norte, surgiu um novo tipo de consumidor, disposto a pagar mais para comprar produtos menos poluentes ou fabricados de acordo com padrões ambientalmente avançados. Houve uma expansão de produtos, embalagens, propagandas e estratégias de marketing voltadas para este novo tipo de consumidor, o "ecologicamente correto". Assim, ampliou-se o campo de oportunidades para os designers.

Este mercado evoluiu tão rapidamente, entre o final da década de 80 e o início da década de 90, que gerou o denominado "consumidor verde", e a necessidade de fiscalizar produtos e empresas que alegam estar em conformidade com os padrões ambientais levando, inclusive, à criação de novos mecanismos de inspeção e certificação. Vale destacar a série ISO 14000 que certifica a qualidade ambiental por meio da ISO 14001.

Considerando o crescimento industrial global, já atingimos há muito tempo os limites do equilíbrio e ingressamos na contagem regressiva para o esgotamento de alguns recursos naturais. Os governos e os mercados pautam o bem estar coletivo no crescimento industrial, contudo, este modelo consumista de prosperidade pela expansão contínua da produção e vendas é insustentável em longo prazo. Mesmo que ainda existam pessoas que acreditam no fato 
de que as novas tecnologias trarão soluções necessárias para os problemas ambientais, percebe-se que as novas tecnologias não serão capazes de resolver os problemas gerados por seus próprios avanços. Nesse contexto, as atividades do design de sistemas e de gestão da qualidade vêm crescendo, pois, considerando os recursos naturais cada vez mais escassos, é necessária uma utilização mais eficiente destes, através do planejamento do consumo e da eliminação do desperdício.

Ainda segundo Cardoso (2008), considerando que o consumo indiscriminado de matérias primas e do acúmulo de materiais não degradáveis descartados no lixo sejam responsáveis por graves impactos ambientais, o aperfeiçoamento de sistemas de reciclagem e de reaproveitamento devem se tornar uma prioridade para o design em nível industrial.

\title{
O Ciclo de Vida dos Produtos
}

Segundo com Manzini e Vezzoli (2011),

\begin{abstract}
Considerar o ciclo de vida quer dizer adotar uma visão sistêmica de produto, para analisar o conjunto dos inputs e dos outputs de todas as suas fases, com a finalidade de avaliar as consequências ambientais, econômicas e sociais (MANZINI; VEZZOLI, 2011, p. 92).
\end{abstract}

Ainda de acordo com esses autores, o ciclo de vida dos produtos é composto das seguintes fases: pré-produção, produção, distribuição, uso e descarte.

A pré-produção é a fase em que são produzidas as matérias primas semielaboradas, e os momentos fundamentais dessa fase são: a aquisição dos recursos; o transporte dos recursos do lugar da aquisição ao da produção; a transformação dos recursos em materiais e em energia. Os recursos primários ou virgens e, os recursos secundários ou reciclados, são os dois tipos de recursos do qual os materiais e energias são produzidos. Sabe-se que os recursos primários provêm diretamente da geosfera, podendo ser renováveis ou não renováveis; os recursos secundários provêm dos descartes e refugos.

A produção é composta de três etapas principais: a transformação dos materiais; a montagem; e o acabamento. Inicia-se com o transporte dos materiais produzidos na fase anterior para a fábrica onde são armazenados e, no devido tempo, transportados para as maquinarias em que se transformam em componentes, e estes são montados com a finalidade de se obter o produto 
final. A partir desta montagem, podem ainda ser realizados diversos processos envolvendo o acabamento. A pesquisa, o desenvolvimento, o projeto, os controles produtivos e a gestão destas atividades, são atribuídos a fase de produção.

A distribuição é composta por três etapas centrais: a embalagem, o transporte e a armazenagem. O produto é embalado para que chegue íntegro nas mãos do usuário final, e o seu transporte pode ser feito por diversos meios. Ele pode ser transportado para um local intermediário, onde será armazenado, ou mesmo ser enviado diretamente para o cliente final. Fazem parte desta fase não somente os consumos e a energia do transporte, mas também o uso dos recursos para a produção dos próprios meios de transporte utilizados, envolvendo também as estruturas para a estocagem e armazenamento dos produtos.

O uso é caracterizado por duas atividades fundamentais: o uso ou consumo; e o serviço. O produto é consumido ou utilizado por um determinado período de tempo e, em muitos casos, além de produzir resíduos e refugos, o seu uso absorve recursos materiais e energéticos. Durante a sua utilização, os produtos podem requerer reparos e manutenção, ou mesmo substituição de partes; estes permanecem em uso até que o usuário o descarte por algum motivo.

No descarte, há uma série de opções sobre o destino final do produto: pode-se recuperar a sua funcionalidade ou de qualquer componente; podemse valorizar as condições do material empregado ou o conteúdo energético do produto; ou ainda optar pela não recuperação do produto. No caso desta última, o seu fim é o despejo em lixos urbanos, ou mesmo disperso no meio ambiente.

Conforme Manzini e Vezzoli (2011),

No caso dos despejos em centros legais de processamento de lixo, os produtos eliminados devem ser devidamente recolhidos e transportados, bem como devem ser tratados aqueles que apresentarem substâncias tóxicas e nocivas (MANZINI; VEZZOLI, 2011, p. 98).

Além das fases do ciclo de vida de um produto, anteriormente citadas, devemos considerar também os ciclos de vida adicionais. Assim, devemos considerar igualmente os ciclos de vida dos outros produtos que integram o ciclo de vida do produto em questão, como por exemplo, considerar o ciclo da embalagem de um determinado produto. 
Segundo Manzini e Vezzoli (2011),

Como todos os produtos, também esses são caracterizados por uma série de trocas com o ambiente (imput e output) e, portanto, determinam impactos ambientais (MANZINI; VEZZOLI, 2011, p. 98).

Esses autores acreditam que, aplicando uma estratégia ambiental consciente, desde as fases iniciais do projeto, é possível evitar ou mesmo limitar os problemas, para não perder tempo com o reparo dos danos já causados. Assim, é fácil unir as vantagens econômicas com as ecológicas.

\section{De acordo com Cardoso (2012),}

Os objetos não morrem; sobrevivem, nem que seja como lixo ou resíduos. É claro que os artefatos podem destruídos, no sentido de serem desagregados a ponto de perderem as especificidades formais que os caracterizam. Surpreende, porém, o quanto são resistentes a isso (CARDOSO, 2012, p. 155).

Ainda segundo este autor, objetos aparentemente frágeis conseguem, muitas vezes, uma sobrevida impressionante. Pode-se observar que em diversos locais do planeta, qualquer escavação do subsolo revela vestígios de eras passadas. Nos últimos 50 anos, a humanidade produziu maior quantidade de artefatos do que em toda a sua história decorrida; estamos em processo de sermos "soterrados" pelo acúmulo de coisas que descartamos como resultado desta superprodução de artefatos.

Considerando que o lixo nada mais é que a matéria desprovida de sentido, então é possível readmitir uma parcela das coisas que tratamos como lixo pela requalificação do seu sentido. Ao adquirirem novos usos, muitas vezes os artefatos ganham uma sobrevida maior do que a sua vida "útil", relativa ao seu primeiro descarte.

Tradicionalmente, os designers vislumbram o ciclo de vida do produto de forma linear, como um fluxograma que passa pelas seguintes etapas: concepção, planejamento, projeto, manufatura, distribuição, venda, uso, descarte. Poucos designers tentam fechar este ciclo, que infelizmente acaba encerrando-se no descarte, contrariando as evidências da necessidade de uma atuação mais consciente do ponto de vista ambiental. Já nos gráficos produzidos por engenheiros, o ciclo de vida do produto é concebido normalmente de modo circular ou cíclico, que vão desde a concepção do produto à sua recuperação ou 
reciclagem, fechando assim este ciclo.

Sabemos que não é fácil conceber o pós-uso, pois a nossa cultura projetiva e fabril está voltada para a fabricação do novo; produtos acabados a partir de matérias primas. Felizmente, alguns buscam trabalhar com matérias primas recicladas e/ou certificadas ambientalmente, o que pode ser considerado como um primeiro passo, porém, um pouco distante dos depósitos de lixo que crescem diariamente. Assim, o projeto do pós-uso, extremamente necessário, abre um imenso desafio que promete revolucionar o pensamento em design.

Inicialmente, o desafio é conceitual, e envolve repensar o ciclo de vida para a nossa era de crise ambiental. Concebemos a existência dos produtos industriais em termos de vida útil, que envolve a parte do ciclo de vida entre a fabricação e o descarte. Vale lembrar que alguns artefatos constituídos por polímeros têm uma vida útil que consiste em dias ou semanas e, demoram milênios para concluírem o processo químico da biodegradação.

Por meio de uma consciência ampliada acerca do ciclo de vida dos produtos, é possível chegar a alguns princípios recomendáveis para o projeto do pós-uso. Estes princípios envolvem: a reversibilidade, a manutenção, a reutilização e reaproveitamento, a durabilidade (valor simbólico).

A reversibilidade é o princípio que se faz presente em produtos cuja forma ou estrutura possa ser mais facilmente desmontada, tendo suas partes componentes aproveitadas de imediato, minimizando assim o acúmulo de lixo. Integram também a este princípio os objetos constituídos por sistemas modulares, pois possuem múltiplas possibilidades de uso, gerando um potencial para estender a sobrevida do produto, que se dá através do rearranjo de suas partes em novas combinações ou, por meio da substituição delas por peças similares ou complementares.

A manutenção, que envolve a possibilidade da troca de peças, é fundamental, pois estende a vida útil do produto. Seria insustentável imaginar, por exemplo, um automóvel, possuidor de uma vida útil relativamente curta, que não permitisse a troca de peças do motor.

A reutilização e o reaproveitamento envolvem o planejamento de objetos de forma plural e polivalente. Um vidro que é utilizado como embalagem para requeijão, se bem projetado, pode ser aproveitado depois como um copo, o que estende em muitas vezes a sua vida útil, considerando a sua reutilização. Também vale lembrar que é raro encontrar em uma lixeira um objeto que exerce múltiplas funções, como por exemplo, um canivete suíço. 
A durabilidade em questão envolve a capacidade de um artefato agregar e simbolizar valores conhecidos, tornando-o mais resistente ao seu descarte. Vale destacar, como exemplo, as canetas-tinteiro e o canivete suíço (citado anteriormente), produtos que dificilmente são encontrados no lixo, devido ao seu valor agregado. Mesmo após o falecimento de seus proprietários, há objetos que ainda assim não são descartados, transferidos como herança, relíquia. Ainda em relação ao princípio da durabilidade, sabe-se que este integra as maiores histórias de sucesso do universo do branding, envolvendo marcas centenárias que comandam fidelidade e reverência no mercado de consumo de luxo.

\section{METODOLOGIA}

\section{Levantamento de Dados}

Para o levantamento de dados, em janeiro de 2012 foi realizada uma pesquisa quantitativa com os coordenadores dos cursos das melhores escolas de design, segundo o Guia do Estudante ${ }^{3}$. Assim, principalmente, dentre os cursos de Design Gráfico, Design de Produto, Design de Interiores e Design de Moda, foram selecionadas somente as universidades e faculdades que obtiveram cinco, quatro ou três estrelas, de acordo com a classificação do Guia.

Segundo o site do Guia do Estudante ${ }^{4}$, para a atribuição de notas aos cursos, há um questionário distribuído para coordenadores dos mesmos e, são selecionados no mínimo seis "pareceristas" (especialistas) para a avaliação dos referidos cursos. Quanto ao conceito, as estrelas que cada curso recebe são o resultado da média das notas recebidas. Um curso considerado bom possui, no mínimo, três estrelas, critério este utilizado para a seleção dos melhores cursos de design para a pesquisa realizada.

\section{Universidades Pesquisadas}

O contato com as escolas se deu por meio de pesquisas via internet, buscando e-mails relativos as mesmas, no qual foi enviado um questionário em conjunto com uma carta de apresentação (ANEXO A).

3 O guia do estudante é uma publicação da Editora Abril que visa, principalmente, orientar o leitor na escolha de sua profissão. Ele oferece informações sobre o mercado de trabalho, faculdades/universidades e cursos de nível superior. A redação da referida publicação entra em contato com cada uma das 2.026 instituições de ensino superior do país para fazer levantamento dos cursos.

4 Disponível em: <http://guiadoestudante.abril.com.br/blogs/melhores-faculdades/tag/ avaliacao-2/>. Acesso em: 31 jan. 2014. 
Dentre as faculdades e universidades pesquisadas, responderam à pesquisa (ANEXO B): Universidade Federal do Paraná (UFPR), Universidade Federal de Pernambuco (UFPE), Universidade Estadual de Londrina (UEL), Universidade Estadual Paulista (UNESP), Universidade São Judas Tadeu (USJT), Universidade Federal de Pelotas (UFPEL), Universidade Luterana do Brasil (ULBRA), Universidade do Vale do Rio dos Sinos (UNISINOS), Universidade Federal de Santa Catarina (UFSC), Centro Universitário Jorge Amado (UNIJORGE), Fundação Mineira de Educação e Cultura (FUMEC), Universidade do Vale do Itajaí (UNIVALI), Pontifícia Universidade Católica de Goiás (PUC), Universidade Federal de Santa Maria (UFSM), Universidade do Estado do Pará (UEPA).

\section{Análise de Dados}

\section{Cursos de design nas 15 escolas pesquisadas}

Considerando as respostas dos questionários enviados às escolas de design pesquisadas, pode-se, quantitativamente, analisar a importância do ecodesign em relação às escolas. O GRÁFICO 1 mostra os 37 cursos de design existentes nas 15 escolas pesquisadas.

GRÁFICO 1 - Cursos de nível superior em design

\section{Cursos de Nível Superior em Design}

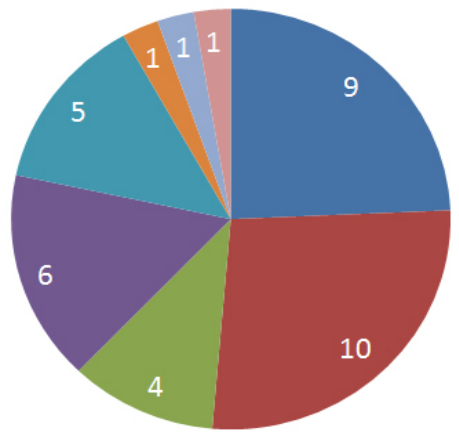

- Design de Produto
— Design Gráfico
— Design de Interiores
- Design de Moda
Design
Design de Animação
Design Digital
Design de Jogos

Fonte: 0 autor.

O GRÁFICO 2 representa o número de escolas de design que possuem disciplina envolvendo o ecodesign em sua matriz curricular.

GRÁFICO 2 - Escolas de design que possuem disciplinaenvolvendo o ecodesign 


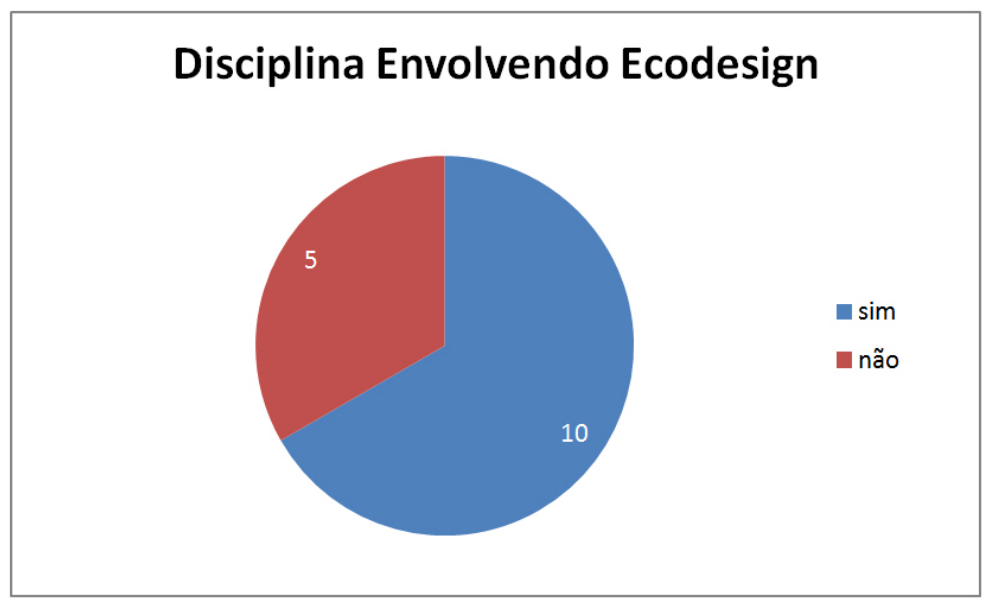

Fonte: o autor.

Escolas de design com disciplina obrigatória envolvendo ecodesign

O GRÁFICO 3 representa o número de escolas de design que possuem o ecodesign como disciplina obrigatória em sua matriz curricular.

GRÁFICO 3 - Escolas de design que possuem disciplina obrigatória envolvendo o ecodesign

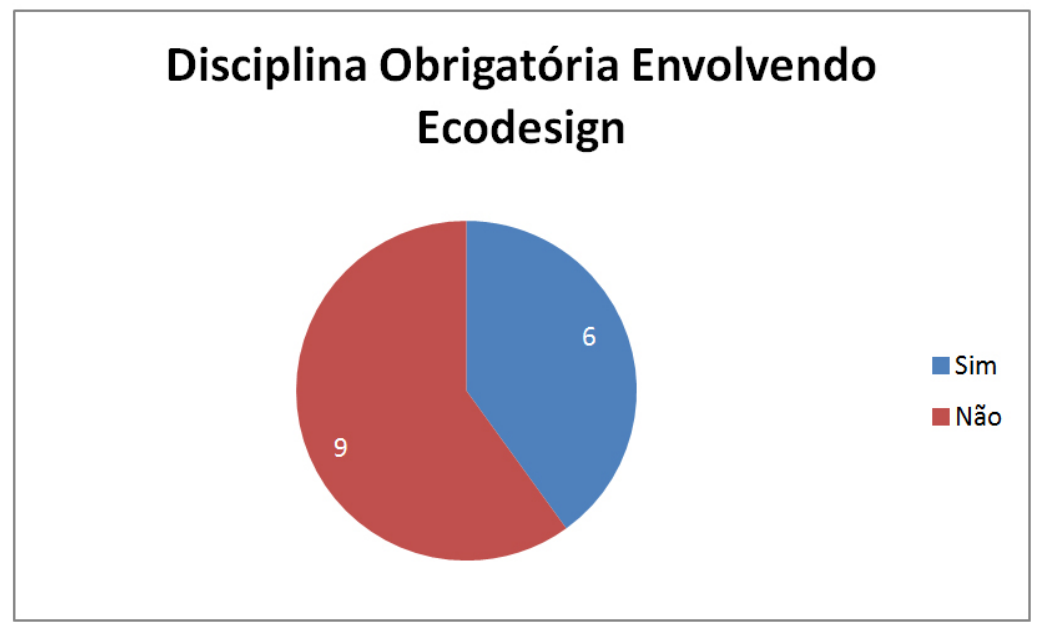

Fonte: 0 autor.

Escolas de design com disciplina optativa envolvendo ecodesign

O GRÁFICO 4 representa o número de escolas de design que possuem o ecodesign como disciplina optativa em sua matriz curricular.

GRÁFICO 4 - Escolas de design que possuem disciplina optativa envolvendo o ecodesign 


\section{Disciplina Optativa Envolvendo Ecodesign}

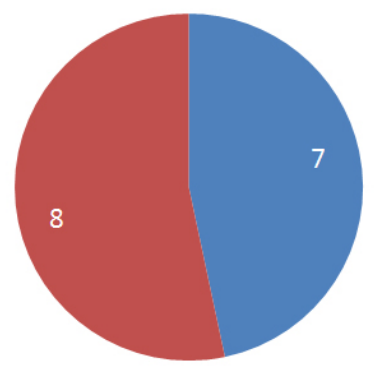

Fonte: 0 autor.

Escolas de design que possuem o ecodesign como tema de pesquisas

O GRÁFICO 5 representa o número de escolas de design que possuem o ecodesign como tema de pesquisas: iniciações científicas, monografias, entre outros.

GRÁFICO 5 - Escolas de design que possuem o ecodesign como tema de pesquisas

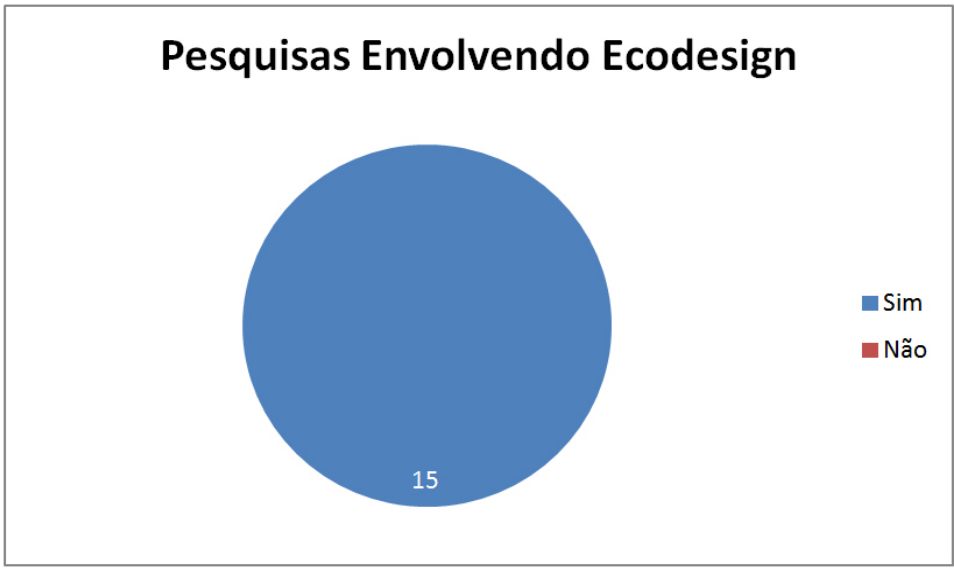

Fonte: 0 autor.

\section{RESULTADOS}

Foram pesquisadas quinze escolas de design, e detectados trinta e sete cursos de design, sendo eles: Design de Produto, Design Gráfico, Design de Interiores, Design de Moda, Design, Design de Animação, Design Digital, Design de Jogos. Ressalta-seque o MEC ${ }^{5}$ não especifica as habilitações em design, 
mas admite modalidades e linhas de formação específica para melhor atender às necessidades do perfil profissional que o mercado ou a região necessitam.

Dez das quinze escolas de design possuem o ecodesign integrado à matriz curricular de seus cursos de design; seis destas escolas possuem o ecodesign como disciplina obrigatória, e sete como disciplina optativa. Vale lembrar que parte das escolas possui o ecodesign como disciplina obrigatória e disciplinas optativas com o mesmo foco.

Por meio da pesquisa realizada nas universidades, pode-se observar a importância global do ecodesign pelo fato de que todas as escolas de design pesquisadas possuem o ecodesign como tema de suas pesquisas. Assim, o ecodesign é abordado em iniciações científicas, monografias, entre outros.

\section{CONSIDERAC̣ÕES FINAIS}

O conceito de sustentabilidade é aplicado ao design quando este consegue suprir as necessidades das pessoas e/ou empresas, visando reduzir o comprometimento ao meio ambiente. Assim, o ecodesign se torna uma importante ferramenta para que o designer aplique o conceito de sustentabilidade em sua atividade projetual, minimizando os impactos ambientais decorrentes de sua atividade. Percebe-se então a importância desta disciplina para a minimização de impactos ambientais negativos.

Desde a década de 80, as preocupações com o meio ambiente ampliaram a área de atuação dos designers. No contexto das preocupações ambientais, as atividades do design de sistemas e de gestão da qualidade vêm crescendo e o ecodesign tem cada vez mais a sua importância reconhecida.

Em relação às quinze escolas de design pesquisadas, percebe-se de forma global a importância do design ecológico, sendo que todas elas abordam o ecodesign como tema de suas pesquisas. Ainda que nas quinze escolas pesquisadas, apenas seis possuem esta disciplina como obrigatória, e dez escolas possuem o ecodesign em sua matriz curricular (entre obrigatórias e optativas). Assim, detecta-se a importância dada ao design ecológico em relação às estas escolas.

Tendo em vista a importância do ecodesign para a minimização de impactos ambientais negativos da atividade do designer, advindos do atual modelo de produção e consumo, torna-se imprescindível que o ecodesign pdf/rces05_04.pdf/>. Acesso em: 31 jan. 2014. 
integre a matriz curricular dos cursos superiores em design como disciplina obrigatória. Assim, o estudante e futuro designer poderão integrar o mercado de trabalho apto a utilizar os conceitos de ecodesign, minimizando assim os possíveis impactos ambientais em sua atividade, atendendo o crescente número de "consumidores verdes" e proporcionando ainda, a maximização da competitividade das empresas.

\section{REFERÊNCIAS}

CARVALHO, Benjamin de Araujo. Ecologia aplicada ao saneamento ambiental. Rio de Janeiro: Associação Brasileira de Engenharia Sanitária e Ambiental: Banco Nacional de Habitação: Fundação Estadual de Engenharia do Meio Ambiente, 1980. ISBN: 85-7022-008-1.

COMISSÃO MUNDIAL SOBRE O MEIO AMBIENTE E DESENVOLVIMENTO. Nosso Futuro Comum. Rio de Janeiro: Editora Fundação Getúlio Vargas, 1988. 430 p.

CARDOSO, Rafael. Uma introdução à história do design. São Paulo: Editora Blucher, 2008, 276p.

CARDOSO, Rafael. Design para um mundo complexo. São Paulo: Cosac Naify, 2012, 264p.

Guia do Estudante: Profissões Vestibular 2012. Editora Abril, 2012.

\section{MANZINI, Ezio; VEZZOLI, Carlo. O Desenvolvimento de Produtos}

Sustentáveis: Os requisitos ambientais dos produtos industriais. São Paulo: Edusp - Editora da Universidade de São Paulo, 2008. 367 p. ISBN: 978-85-314-0731-4. Título original: Losviluppodiprodottisostenibili: I requisitiambientali dei prodittiindustriali.

PÊGO, Kátia Andréa Carvalhaes. Guia para inserção dos parâmetros ambientais no design de móveis de madeira. Barbacena: EdUEMG; Livronovo, 2010, 36 p. ISBN: 978-856257807-6.

RIBEIRO, Hélcio Pupo. Artes Industriais: do decorativo Rococó ao Funcionalismo Industrial. Bauru: Editora Jalovi, 1985, 138p. 